\title{
Obtenção de cerâmicas de alumina com porosidade graduada processadas pelas técnicas de colagem de barbotina e freeze casting
}

\author{
(Production of alumina ceramics with graded porosity \\ processed by slip casting and freeze casting)
}

\author{
G. A. de Carvalho ${ }^{1 *}, A . S . A$. Chinelatto $^{I}$ \\ ${ }^{1}$ Universidade Estadual de Ponta Grossa, Av. Gen. Carlos Cavalcanti 4748, Ponta Grossa, PR, Brasil
}

\begin{abstract}
Resumo
O objetivo foi estudar o processamento de materiais cerâmicos de alumina com porosidade graduada a partir das técnicas de freeze casting e colagem de barbotina sequencial, utilizando hidróxido de alumínio como fase de sacrifício. Após conformação, a porosidade foi caracterizada por microscopia eletrônica de varredura, medidas de porosidade aparente pelo princípio de Arquimedes e distribuição de tamanho e tamanho médio de poros pela técnica de porosimetria de mercúrio. Foi avaliada a resistência mecânica das amostras a partir de ensaio de compressão. A caracterização permitiu a confirmação da relação da microestrutura entre as camadas das amostras processadas isoladamente e suas respectivas camadas nos materiais com porosidade graduada. Foi observada uma boa interação interfacial entre as camadas das amostras graduadas. As porosidades obtidas pelos dois métodos foram distintas devido às diferentes morfologias obtidas, sendo que pela técnica de colagem de barbotina, os poros apresentaram menores tamanhos, com poucas interconexões e na técnica de freeze casting os poros apresentaram-se intralamelares com formato alongado e interligados entre si. Os valores de porosidade e resistência à compressão apresentaram resultados distintos para cada técnica. A amostra graduada processada por freeze casting apresentou maior porosidade e resistência mecânica quando comparada à amostra processada por colagem. As duas técnicas utilizadas mostraram ser eficientes para produzir materiais com graduação de porosidade.

Palavras-chave: colagem de barbotina, alumina, hidróxido de alumínio, freeze casting, porosidade graduada.
\end{abstract}

\begin{abstract}
The objective was to study the processing of alumina ceramic materials with graded porosity produced by freeze casting and slip casting with aluminum hydroxide as a porogenic agent. After processing of the samples, porosity was studied by scanning electron microscopy, apparent porosity by the Archimedes' principle, and size and average pore size by mercury porosimetry. The mechanical strength of the samples was studied through compression testing. The characterization allowed confirmation of the relation between the samples processed individually and their respective layer in materials with graded porosity. The samples also showed good interfacial interaction between the layers of the graded materials. The porosities obtained by both methods were distinct due to different morphologies; by slip casting, the pores showed smaller sizes with few interconnections and by freeze casting, pores were interlayered with elongated and interconnected morphology. Porosity and compressive strength values were different for each technique. The graded sample processed by freeze casting showed higher porosity and compressive strength when compared to the sample processed by slip casting. Both techniques showed to be efficient for the production of graded porosity material.
\end{abstract}

Keywords: slip casting, alumina, aluminum hydroxide, functionally graded materials.

\section{INTRODUÇÃO}

Materiais cerâmicos porosos vêm sendo utilizados e preferidos para diversas aplicações devido às suas propriedades de isolamento térmico, permeação de gases e fluidos, baixa densidade e biocompatibilidade, podendo ser empregados como filtros, catalisadores, eletrodos para células a combustíveis e para reposição óssea [1-8]. Dentre os materiais cerâmicos, a alumina é um dos materiais mais promissores para a obtenção de produtos com elevada porosidade devido à elevada resistência mecânica, o que

*gus.decarvalho@gmail.com

Dhttps://orcid.org/0000-0002-9387-9119 permite o processamento de produtos com porosidades de até aproximadamente $90 \%$ sem que haja o colapso dos mesmos. Além disso, apresenta inércia química, o que permite ser utilizada em diferentes áreas [5, 9]. Para obtenção de cerâmicas de alumina porosas, podem ser utilizados diversos processos, os quais podem ser divididos em três categorias principais: réplica, espumação e fase de sacrifício. No processo de réplica são inseridos precursores, normalmente poliméricos, que formam estruturas celulares no interior de suspensões cerâmicas. A suspensão envolve o material e, consequentemente, a estrutura e, após a volatilização do componente e sinterização, resta o material cerâmico com a estrutura porosa relativa ao material utilizado no interior [10]. Para o método da espumação, os poros são formados a partir da incorporação de ar dentro das suspensões 
cerâmicas. Quanto maior a quantidade de ar inserida na suspensão, maior é a quantidade de porosidade final obtida [10]. O terceiro método é o processo que utiliza uma fase de sacrifício. Este processo utiliza-se da formação de um sólido bifásico com uma fase cerâmica e uma segunda fase, chamada fase de sacrifício. Após a conformação do material, a fase de sacrifício é retirada do material, normalmente por volatilização, restando os poros na microestrutura $[10,11]$.

Um dos compostos que pode ser utilizado como fase de sacrifício é o hidróxido de alumínio $\left[\mathrm{Al}(\mathrm{OH})_{3}\right]$, devido à decomposição com o aumento da temperatura, resultando em vapor de água, cujo efeito é o surgimento de porosidade na matriz. Uma das principais vantagens em utilizá-lo é o fato de ser um precursor do óxido de alumínio [11-16]. Alguns autores [11-21] determinaram que a temperatura em que ocorre a decomposição do hidróxido de alumínio está entre 200 e $400{ }^{\circ} \mathrm{C}$ e mostraram que a temperatura e a forma como a decomposição ocorre é dependente da fase cristalina. Diferentes fases do $\mathrm{Al}(\mathrm{OH})_{3}$, como diásporo, bayerita e gibbsita, mostram evoluções de fase distintas com o aquecimento devido às diferenças na mobilidade de seus átomos e difusividade nas estruturas cristalinas e presença de impurezas $[13,15,17]$, porém, acima de aproximadamente $1100{ }^{\circ} \mathrm{C}$ há a completa transformação do hidróxido de alumínio em $\alpha$-alumina, a fase mais estável da mesma. O tamanho de partículas e a taxa de aquecimento também são variáveis importantes neste processo e afetam o comportamento porogênico do $\mathrm{Al}(\mathrm{OH})_{3}$ em matrizes de $\alpha$-alumina [16, 18, 19]. Souza e Salomão [19] estudaram o comportamento porogênico do $\mathrm{Al}(\mathrm{OH})_{3}$ (gibbsita) com diferentes tamanhos médios de partícula em matrizes de alumina e observaram que suas propriedades físicas são afetadas pelo tamanho médio das partículas de $\mathrm{Al}(\mathrm{OH})_{3}$, pela porosidade inicial no estado a verde e pela temperatura de sinterização. As composições com partículas de $\mathrm{Al}(\mathrm{OH})_{3}$ maiores apresentaram os maiores níveis de porosidade e menor resistência mecânica, enquanto as composições com tamanho de partículas menores apresentaram uma maior densificação devido à maior reatividade das partículas formadas após a desidroxilação do $\mathrm{Al}(\mathrm{OH})_{3}$, resultando em amostras menos porosas e com maior resistência mecânica. Dois tipos de poros podem ser formados pela decomposição do hidróxido de alumínio; um deles, a partir da decomposição das hidroxilas e formação de vapor de água, gera vazios no interior da peça formando poros de tamanho grande e um segundo, pela interação das partículas de hidróxido de alumínio, transformadas em alumina, com as partículas de alumina da matriz, que geram poros pequenos durante a sinterização [14, 18, 19]. Outra característica importante é a similaridade do comportamento reológico do hidróxido de alumínio e alumina em suspensão quando se utilizam dispersantes eletroestéricos, além de similaridade de comportamento em potencial zeta. [11, 19-21]. Ambos demonstram regiões ótimas de dispersão em pHs semelhantes. Isso facilita a sua aplicabilidade como fase de sacrifício em processamentos que utilizam suspensões, devido à necessidade de controle reológico, tais como no processo de colagem de barbotina, tape casting efreeze casting $[5,7,18-21]$.
Um outro processo que se mostra promissor para a produção de cerâmicas porosas é o freeze casting, o qual permite a obtenção de materiais com porosidades elevadas a partir do congelamento de uma suspensão cerâmica seguido de liofilização. Este se encaixa como um processo de réplica, dentre os três tipos citados anteriormente. O processo de obtenção de um material poroso por freeze casting ocorre inicialmente pela preparação da suspensão cerâmica à temperatura ambiente e à pressão atmosférica. Após isso, a suspensão é congelada a partir de elevadas taxas de redução da temperatura, da ordem de $6{ }^{\circ} \mathrm{C} / \mathrm{min}$ [22]. Durante o congelamento ocorre o crescimento dos cristais de solvente e o encarceramento das partículas cerâmicas entre eles. Com a suspensão congelada é realizado, então, o processo de liofilização, que permite a sublimação de todo o solvente presente no material, restando as partículas cerâmicas empacotadas. Ao final, o material é sinterizado [5, 23]. Em geral, os estudos mostram uma relação proporcional entre a quantidade de sólido em suspensão e a porosidade obtida ao final do processo freeze casting [24-44]. Além disso, demonstrou-se que, geralmente, a porosidade obtida no material processado é aberta, pois os poros são formados a partir do crescimento dos cristais de solvente que intermeiam as partículas sólidas [5, 18, 19].

Atualmente, também vêm sendo estudados materiais com porosidade graduada, nos quais a porosidade se altera ao longo de uma das dimensões do material [45-48]. Estes materiais são denominados materiais com gradiente funcional (MGF), pois apresentam propriedade e/ou composição que variam dentro do volume do material [49-52]. Esses materiais começaram a ser estudados há mais de 40 anos, a fim de solucionar problemas de aplicação de engenharia [53]. Os MGFs evitam, principalmente, a presença de tensões interfaciais, que estariam presentes caso fosse feita a união de diferentes partes para manter a graduação de propriedades [54-56]. A produção de MGFs porosos pode ser feita utilizando diferentes técnicas, como por exemplo, coprensagem, tape casting, freeze casting e colagem de barbotina. Os materiais produzidos podem apresentar porosidade em quantidades variáveis, tendo poros com formatos e tamanhos diferentes, o que pode gerar um gradiente de dureza, densidade, condutividade térmica, ou módulo de elasticidade na extensão do material [45-56], o que permite um vasto espectro de possibilidades de aplicação. Assim, o objetivo desse trabalho foi produzir cerâmicas de alumina com gradiente de porosidade obtidas por dois processos: colagem de barbotina sequencial utilizando hidróxido de alumínio como agente porogênico e processo de freeze casting, utilizando congelamentos sequenciais. Os dois processos foram utilizados visando comparar as morfologias de poro, porosidade total e aparente, resistência mecânica e tipo de fratura entre os materiais obtidos.

\section{MATERIAIS E MÉTODOS}

Foi utilizado como matéria-prima um pó de alumina (CT 3000 SG, Almatis, Alemanha) de pureza 99,82\%. Foi utilizado como agente formador de poros um hidróxido de 
alumínio (Hydral 710, Almatis, Alemanha) de pureza 99,5\%, tendo com fase cristalina a gibbsita, $\mathrm{Al}(\mathrm{OH})_{3}$. A alumina e o hidróxido de alumínio foram caracterizados por medidas de tamanho médio e distribuição de tamanho de partículas pela técnica de difração a laser utilizando um granulômetro (mod. 92, Cilas) e por espectroscopia de fluorescência de raios X para determinação da sua composição química utilizando um espectrômetro (EDX-700, Shimadzu). O hidróxido de alumínio foi caracterizado também por análise térmica diferencial e termogravimétrica (ATD/TG) para verificação da sua decomposição com a variação da temperatura. A análise foi feita até $1200{ }^{\circ} \mathrm{C}$ com taxa de aquecimento de $10{ }^{\circ} \mathrm{C} / \mathrm{min}$ em um analisador térmico (STA 409EP, Nestzch).

Foram utilizadas duas técnicas para a produção das amostras porosas e amostras porosas graduadas: a técnica de sacrifícioutilizandohidróxido dealumínioe a técnica de freeze casting. As amostras porosas utilizando a fase de sacrifício foram feitas por colagem de barbotina. As suspensões utilizadas para o processo de colagem de barbotina foram preparadas com 35\% em volume de sólidos em suspensão, variando-se a relação entre alumina e a fase de sacrifício. As quantidades de hidróxido de alumínio utilizadas foram de $25 \%, 50 \%$ e $75 \%$ em volume, representadas na Tabela I como AH7525, AH5050 e AH2575, respectivamente. Além das amostras com fase de sacrifício, para efeito de comparação, foi preparada uma amostra de alumina sem fase de sacrifício, com a mesma quantidade em volume de sólidos em suspensão, de 35\%. A amostra é representada na Tabela I como AL100. Para o processo de freeze casting foram utilizadas suspensões de alumina com variadas quantidades de sólido. As quantidades de sólido utilizadas foram de $20 \%, 25 \%, 30 \%, 35 \%$ e $40 \%$, representadas na Tabela I como AL20, AL25, AL30, AL35 e AL40. Para a preparação das suspensões de alumina, inicialmente foi determinada a curva de defloculação para uma suspensão com 35\% em volume de sólidos utilizando o dispersante de poliacrilato de amônio (821-A Darvan, Vanderbilt Miner.); as medidas

Tabela I - Composições estudadas (\% em volume) para ambos os processos, com suas respectivas denominações.

[Table I - Compositions studied (volume \%) for both processes with their respective codes.]

\begin{tabular}{cccc}
\hline Amostra & $\begin{array}{c}\text { Fração de } \\
\text { sólidos }\end{array}$ & $\begin{array}{c}\text { Fração de } \\
\text { alumina }\end{array}$ & $\begin{array}{c}\text { Fração de } \\
\text { hidróxido de } \\
\text { alumínio }\end{array}$ \\
\hline AL100 & 35 & 100 & 0 \\
AH7525 & 35 & 75 & 25 \\
AH5050 & 35 & 50 & 50 \\
AH2575 & 35 & 25 & 75 \\
AL20 & 20 & 100 & 0 \\
AL25 & 25 & 100 & 0 \\
AL30 & 30 & 100 & 0 \\
AL35 & 35 & 100 & 0 \\
AL40 & 40 & 100 & 0 \\
\hline
\end{tabular}

foram feitas em um viscosímetro (RVDV-II, Brookfield). A quantidade de dispersante utilizada foi de $2 \%$ em massa da parte sólida. Além do dispersante, também foi adicionado à suspensão um ligante orgânico (Duramax B1022, Dow) na quantidade de $5 \%$ em massa da parte sólida, a fim de manter a estabilidade estrutural das amostras a verde.

Foram produzidas amostras individuais de cada uma das composições estudadas, tanto para o processo de colagem de barbotina quanto para o de freeze casting, com a finalidade de comparar a morfologia das mesmas com as suas respectivas camadas no material graduado. Para o processo de colagem de barbotina, foram utilizados moldes cilíndricos de 1,5 $\mathrm{cm}$ de diâmetro por $2 \mathrm{~cm}$ de altura fixados em uma base de gesso. Um desenho esquemático da montagem é mostrado na Fig. 1a. O controle de espessura da amostra para o processo de colagem de barbotina foi realizado a partir do tempo de colagem. Nas amostras individuais, a suspensão foi vertida no molde e mantida por 25 min; na sequência foi retirado o excesso de suspensão e, então, as amostras conformadas foram mantidas nos moldes por $24 \mathrm{~h}$ para secagem. Para as amostras graduadas, foi inicialmente vertida a suspensão referente à composição AL100 no molde, mantida por 6 min; na sequência foi retirado o excesso de suspensão e vertida a próxima composição, AH7525, que foi mantida também por 6 min e retirado o excesso de suspensão. O processo foi repetido para as suspensões de composições AH5050 e AH2575 até a formação das quatro camadas. Desta forma,
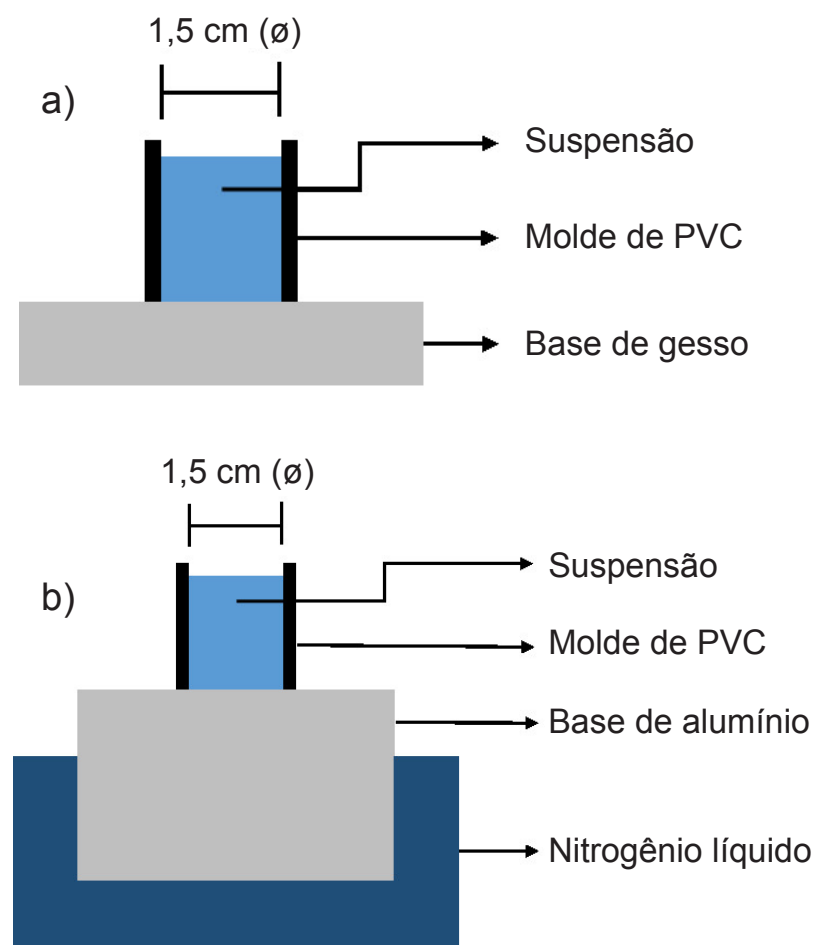

Figura 1: Desenhos esquemáticos dos moldes e bases utilizados para conformação das amostras por: a) colagem de barbotina; e b) técnica de freeze casting.

[Figure 1: Schematic drawings of the molds and bases used for forming the samples by: a) slip casting; and b) freeze casting technique.] 
o tempo total de colagem foi de $24 \mathrm{~min}$, garantindo às amostras graduadas espessuras semelhantes às amostras individuais. As amostras conformadas foram mantidas nos moldes por $24 \mathrm{~h}$ para secagem, de modo semelhante às amostras processadas individualmente.

Para o processo de freeze casting foram utilizados moldes cilíndricos de PVC de $1,5 \mathrm{~cm}$ por $2 \mathrm{~cm}$ de altura fixados em uma base de alumínio. Foi utilizada vaselina sólida para lubrificação dos moldes e fixação na base de alumínio. A parte inferior da base de alumínio foi mergulhada em nitrogênio líquido e agiu como condutor térmico para o congelamento da suspensão. Um desenho esquemático da montagem é mostrado na Fig. 1b. O controle de espessura da amostra no processo de colagem de barbotina foi realizado pelo volume de suspensão colocado para congelamento no molde. Nas amostras individuais foram depositados $25 \mathrm{~mL}$ de suspensão no molde. Na amostra graduada foram utilizados $5 \mathrm{~mL}$ de suspensão por camada. Nas amostras individuais, foram vertidos os 25 $\mathrm{mL}$ de suspensão no interior do molde e mergulhada a base de alumínio em nitrogênio líquido. $\mathrm{O}$ molde foi mantido em nitrogênio líquido até o congelamento completo da suspensão. Após isso, a amostra foi desmoldada e transferida para um ultrafreezer até a realização do processo de liofilização com um liofilizador (LD1500, Terroni) para obtenção das amostras porosas. Para as amostras graduadas, inicialmente foram vertidos os $5 \mathrm{~mL}$ da suspensão referente à composição AL40 no molde e, então, mergulhada a base de alumínio em nitrogênio líquido. O molde foi mantido mergulhado em nitrogênio até o congelamento completo da suspensão. Após o congelamento completo da primeira camada, foram vertidos $5 \mathrm{~mL}$ da próxima composição, AL35, e repetido o processo até congelamento completo da camada. O processo foi repetido para as composições AL30, AL25 e AL20, até a formação das cinco camadas. Após a conformação de todas as camadas, as amostras foram desmoldadas em processo semelhante às amostras individuais, sendo mantidas em ultrafreezer até a realização da liofilização, que foi realizada no mesmo equipamento das amostras individuais.

A partir das análises de ATD/TG foi possível determinar a curva de sinterização das amostras que utilizaram o hidróxido de alumínio como fase de sacrifício. No ciclo de sinterização utilizado, inicialmente as amostras foram aquecidas até $600^{\circ} \mathrm{C}$ por $1 \mathrm{~h}$ utilizando uma taxa de $5^{\circ} \mathrm{C} / \mathrm{min}$ para decomposição do hidróxido de alumínio e eliminação do ligante e, em seguida, foram aquecidas até a temperatura de sinterização do material, a $1500{ }^{\circ} \mathrm{C}$, com patamar de $2 \mathrm{~h}$, a uma taxa de $10{ }^{\circ} \mathrm{C} / \mathrm{min}$. Após o patamar de $2 \mathrm{~h}$, o forno foi resfriado a uma taxa de $10{ }^{\circ} \mathrm{C} / \mathrm{min}$. A sinterização foi feita num forno elétrico (F1800, EDG). A Eq. A indica a reação de decomposição térmica do hidróxido de alumínio e uma perda de massa de $34 \%$ pode ser observada, devido à liberação endotérmica de vapor de água [19]. Foi utilizada a mesma curva de queima para as amostras processadas pelo processo de freeze casting, visando a retirada do ligante no patamar de $600{ }^{\circ} \mathrm{C}$ e posterior sinterização.

$$
2 \mathrm{Al}(\mathrm{OH})_{3} \rightarrow \mathrm{Al}_{2} \mathrm{O}_{3}+3 \mathrm{H}_{2} \mathrm{O}
$$

As amostras sinterizadas foram caracterizadas por medidas de porosidade aparente e densidade aparente utilizando o processo de imersão em líquido baseado no princípio de Arquimedes. A partir desses resultados foram avaliadas também as porosidades fechada e total. Foram feitas três amostras para cada composição, assim como para as amostras graduadas. Os valores de porosidade aberta (PA) das amostras foram determinados a partir de:

$$
\mathrm{PA}(\%)=\frac{\mathrm{m}_{\mathrm{u}}-\mathrm{m}_{\mathrm{s}}}{\mathrm{m}_{\mathrm{u}}-\mathrm{m}_{\mathrm{i}}} .100
$$

no qual $\mathrm{m}_{\mathrm{u}}$ é a massa da amostra úmida, $\mathrm{m}_{\mathrm{s}}$ a massa da amostra seca e $m_{i}$ a massa da amostra imersa em água. Os valores de porosidade fechada (PF) foram determinados a partir de:

$$
\mathrm{PF}=\mathrm{PT}-\mathrm{PA}
$$

no qual PT é a porosidade total e pode ser calculada a partir de:

$$
\mathrm{PT}=\left(1-\frac{\mathrm{DA}}{\mathrm{D}_{\text {Alumina }}}\right) \cdot 100
$$

sendo $\mathrm{D}_{\text {Alumina }}$ a densidade teórica da alumina e DA a densidade aparente, calculada por:

$$
\mathrm{DA}=\frac{\mathrm{m}_{\mathrm{s}}}{\mathrm{m}_{\mathrm{u}}-\mathrm{m}_{\mathrm{i}}} \cdot \rho_{\text {agua }}
$$

O tamanho médio e a distribuição de tamanho de poros foram medidos por porosimetria de mercúrio (Autopore IV, Micromeritics). As análises foram realizadas nas amostras individuais, relativas a cada uma das composições, assim como nas amostras graduadas. A morfologia de poros foi observada em superfícies fraturadas por meio de microscopia eletrônica de varredura (MEV) utilizando um microscópio (VEGA 3, Tescan). A análise foi realizada na seção transversal da amostra, possibilitando uma melhor análise das interfaces entre as camadas das amostras graduadas. A resistência mecânica foi analisada por ensaio de compressão utilizando uma máquina universal de ensaios (AGI $10 \mathrm{kN}$, Shimadzu) com taxa de carregamento de $0,5 \mathrm{~mm} / \mathrm{min}$. Foram realizados três ensaios para cada composição, assim como para cada uma das amostras graduadas. Após rompimento das amostras, as superfícies de fratura foram analisadas por microscopia ótica de baixa magnificação em microscópio (SZ61, Olympus) para verificar a presença de lascamento ou separação de camadas das amostras graduadas.

\section{RESULTADOS E DISCUSSÃO}

A Tabela II apresenta os resultados da análise química das matérias-primas utilizadas. Observou-se que as duas 
matérias-primas apresentaram purezas relativamente altas. Na Figs. 2a e 2b estão representadas as curvas das distribuições de tamanho de partícula da alumina e do hidróxido de alumínio, respectivamente. O tamanho médio de partículas $\left(D_{50}\right)$ foi de $0,49 \mu$ m para a alumina e de $1,27 \mu \mathrm{m}$

Tabela II - Composição química (\% em massa) das matériasprimas utilizadas.

[Table II - Chemical composition (wt\%) of raw materials.]

\begin{tabular}{ccc}
\hline Óxido & Hidróxido de alumínio & Alumina \\
\hline $\mathrm{Al}_{2} \mathrm{O}_{3}$ & 99,60 & 99,65 \\
$\mathrm{SiO}_{2}$ & 0,01 & 0,06 \\
$\mathrm{Fe}_{2} \mathrm{O}_{3}$ & 0,05 & 0,03 \\
$\mathrm{CaO}$ & 0,07 & 0,07 \\
$\mathrm{Na}_{2} \mathrm{O}$ & 0,24 & 0,17 \\
$\mathrm{MgO}$ & - & 0,04 \\
\hline
\end{tabular}

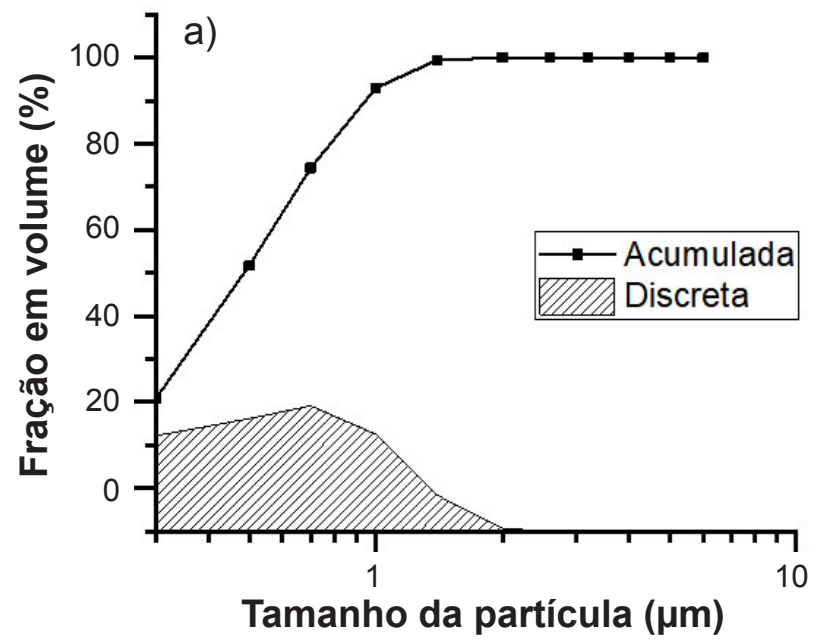

para o hidróxido de alumínio, indicando que o hidróxido de alumínio, utilizado como agente porogênico, teve tamanho de partícula médio maior que o da alumina. Percebeuse também uma distribuição ligeiramente mais estreita de tamanho de partícula para a alumina, sendo que o $\mathrm{D}_{10}$ foi $0,24 \mu \mathrm{m}$ e o $\mathrm{D}_{90}$ foi $0,95 \mu \mathrm{m}$, enquanto para o hidróxido de alumínio, o $\mathrm{D}_{10}$ foi $0,50 \mu \mathrm{m}$ e o $\mathrm{D}_{90}$ foi $2,52 \mu \mathrm{m}$. A análise foi realizada até o tamanho de partícula de $0,3 \mu \mathrm{m}$, que foi o limite de detecção do equipamento utilizado.

Os resultados da análise térmica diferencial (ATD) e termogravimétrica (TG/DTG) do hidróxido de alumínio, cuja fase cristalográfica foi a gibbsita, estão apresentados nas Figs. 3a e 3b, respectivamente. Pela curva de ATD (Fig. 3a) observou-se um forte pico endotérmico em torno de 320 ${ }^{\circ} \mathrm{C}$ e dois pequenos picos endotérmicos a aproximadamente 200 e $520{ }^{\circ} \mathrm{C}$. O pico endotérmico a $320{ }^{\circ} \mathrm{C}$ foi associado à desidroxilação da gibbsita $\mathrm{Al}(\mathrm{OH})_{3}$ e à formação da $\chi-\mathrm{Al}_{2} \mathrm{O}_{3}$. Nessa decomposição, a gibbsita também produziu pequenas quantidades de boehmita $(\mathrm{AlOOH})$ [57], sendo

Figura 2: Curvas de distribuição de tamanhos de partícula de: a) alumina; e b) hidróxido de alumínio.

[Figure 2: Particle size distribution curves of: a) alumina; and b) aluminum hydroxide.]
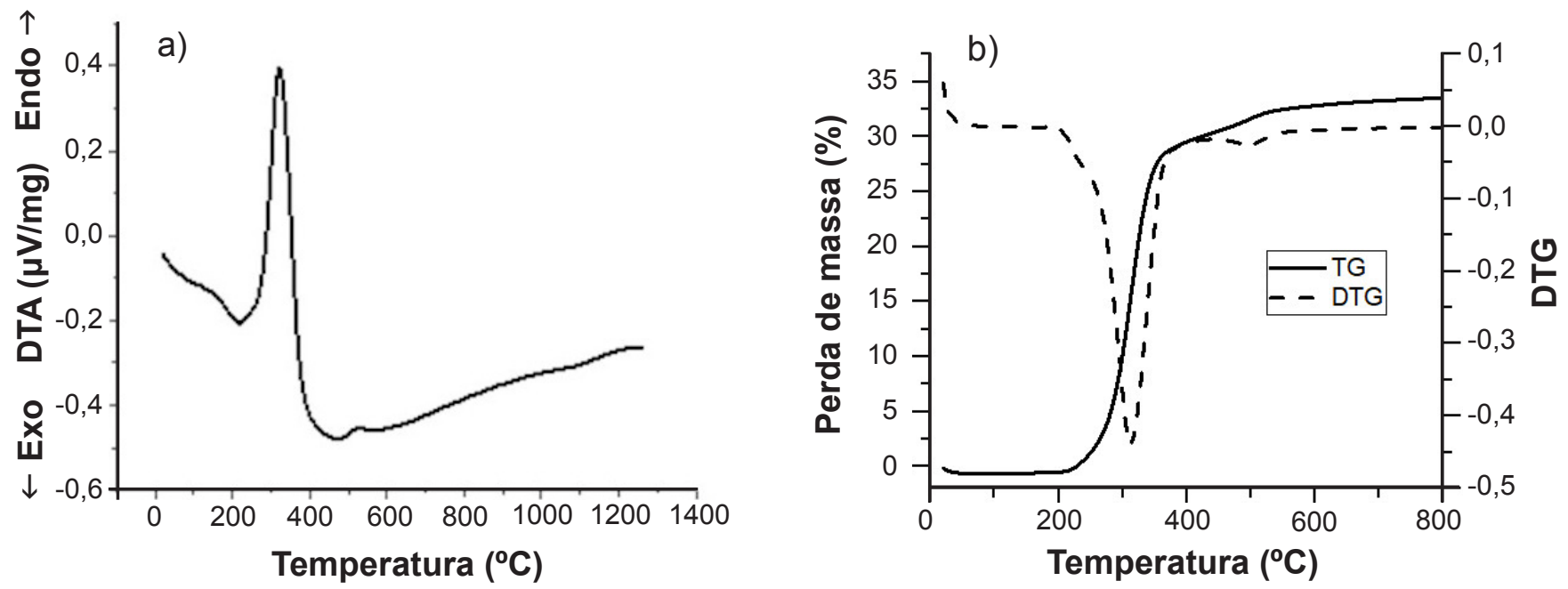

Figura 3: Curvas de ATD (a) e TG/DTG (b) para o hidróxido de alumínio.

[Figure 3: DTA (a) and TG/DTG (b) curves of aluminum hydroxide.] 
que os pequenos picos endotérmicos observados em torno de 200 e $520{ }^{\circ} \mathrm{C}$ podem ser associados, respectivamente, à formação e à decomposição dessa boehmita [58]. Pela análise termogravimétrica (Fig. 3b), observou-se que houve uma perda de massa significativa entre 200 e $550^{\circ} \mathrm{C}$, a qual foi atribuída à decomposição do hidróxido de alumínio. A partir de aproximadamente $600{ }^{\circ} \mathrm{C}$ não ocorreu mais perda de massa acentuada, sendo a perda de massa total, a aproximadamente $1100{ }^{\circ} \mathrm{C}$, de $32 \%$. Como demonstrado anteriormente na Eq. A, é esperada uma perda de massa de aproximadamente $34 \%$, representativa da massa de água perdida durante a decomposição do hidróxido de alumínio. Dessa forma, o resultado obtido na análise é condizente com o esperado, e foi em acordo com outros trabalhos encontrados na literatura [44-46]. A DTG, que é a derivada da curva de TG, confirmou que a decomposição da gibbsita ocorreu em $320^{\circ} \mathrm{C}$ com uma grande perda de massa e que em torno de $520^{\circ} \mathrm{C}$ ocorreu provavelmente a decomposição da boehmita, como mostrado na curva de ATD.

A Fig. 4 apresenta os resultados da porosidade aparente (PA), porosidade fechada (PF) e porosidade total (PT) de todas as amostras individuais. Os resultados demonstraram a formação de porosidade crescente com o aumento da quantidade de hidróxido de alumínio, confirmando a efetividade da fase utilizada como fase de sacrifício. Esses resultados mostraram também o aumento da porosidade com a redução da quantidade de sólidos na suspensão nas amostras preparadas por freeze casting, o que está condizente com a literatura $[32,33,35,38]$. Pôde-se observar também que as amostras processadas a partir de freeze casting alcançaram maiores valores de porosidade em relação às amostras obtidas a partir da colagem de barbotina. A maior diferença se encontrou nos valores da porosidade aberta. Isso ocorreu devido à diferença na formação de porosidade dos dois processos utilizados. Com o uso da fase de sacrifício, a porosidade foi gerada pela decomposição das partículas de hidróxido de alumínio, na qual parte do volume originalmente ocupada pelas partículas de $\mathrm{Al}(\mathrm{OH})_{3}$ foi reduzida, pois a fase de $\mathrm{Al}_{2} \mathrm{O}_{3}$ formada apresenta maior densidade $\left[\mathrm{QAl}_{2} \mathrm{O}_{3}=3,8-4,0 \mathrm{~g} / \mathrm{cm}^{3} ; \mathrm{QAl}(\mathrm{OH})_{3}=2,4 \mathrm{~g} / \mathrm{cm}^{3}\right][17-19,21]$. Essa porosidade gerada foi geralmente associada ao tamanho de partícula do hidróxido de alumínio utilizado. No processo de freeze casting, a porosidade foi decorrente do crescimento dos cristais de solvente durante o congelamento, os quais foram posteriormente liofilizados, gerando os poros em seu lugar [22, 23, 25]. Nesse processo, a estrutura de poros obtida foi similar a uma rede de canais unidirecionais, na qual os poros foram uma réplica do solvente utilizado. As partículas que estavam dispersas no solvente, durante o congelamento, foram expulsas do sólido recém-formado, empilhando-se entre os cristais formados. No caso da água, tem-se um crescimento lamelar maior nos cristais de gelo paralelos à direção de resfriamento. Desta forma têm-se cristais lamelares grandes, verticais, com pequenas lamelas entre estes cristais, na direção perpendicular à de resfriamento [23].

A diferença de porosidade entre as amostras com $25 \%$

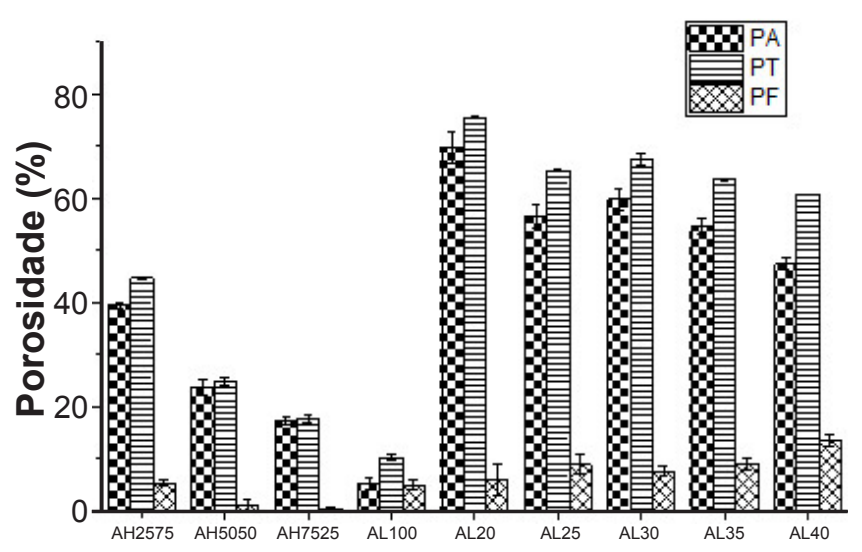

Figura 4: Porosidade aparente (PA), porosidade fechada (PF) e porosidade total (PT) das amostras conformadas.

[Figure 4: Apparent porosity (PA), closed porosity (PF), and total porosity $(P T)$ of the samples.]

(AH7525) e 50\% (AH5050) de hidróxido de alumínio foi de $6,4 \%$, enquanto a diferença entre as amostras com $50 \%$ (AH5050) e 75\% (AH2575) de hidróxido de alumínio foi de $15,9 \%$. Essa diferença pode ter ocorrido devido à formação de poros com geometrias diferentes, os quais possuíram características termodinâmicas diferentes. De acordo com a teoria de sinterização [59], existe um número de coordenação crítica, $\mathrm{Nc}$, que é o número de grãos ao redor de um poro durante a sinterização. Se o número de coordenação é maior que o $\mathrm{Nc}$, os poros tendem a crescer, porém, se o número de coordenação é menor que $\mathrm{Nc}$, os poros tendem a diminuir. Assim, quando houve maior a quantidade de hidróxido de alumínio, o número de coordenação ao redor dos poros foi maior que $\mathrm{Nc}$ e os poros tenderam a crescer e, quando houve maior quantidade de alumina, os poros tenderam a diminuir, como observado por Deng et al. [18]. Quando se comparou as amostras contendo hidróxido de alumínio com a amostra AL100, contendo apenas alumina, observou-se que, como esperado, ela apresentou uma menor porosidade total (PT), porém a sua porosidade fechada foi maior que as amostras contendo hidróxido de alumínio. Isso ocorreu devido à amostra AL100, por não conter o agente porogênico, quando sinterizada a $1500{ }^{\circ} \mathrm{C}$, atingiu o seu estágio final de sinterização, no qual a porosidade aberta foi diminuída intensamente, restando uma porosidade residual fechada a ser eliminada [60].

As Figs. 5 e 6 apresentam as curvas de distribuição de tamanho de poros das amostras individuais obtidas utilizando como fase de sacrifício o hidróxido de alumínio e produzidas por freeze casting, respectivamente. As amostras que utilizaram hidróxido de alumínio (Fig. 5) apresentaram distribuição e tamanho de poros similares, variando entre 0,1 a $1 \mu \mathrm{m}$ e apresentaram tamanho médio semelhante (entre 0,24 e $0,37 \mu \mathrm{m}$ ). Com relação às amostras preparadas por freeze casting, pode ser observada em todas as curvas apresentadas na Fig. 6 uma quantidade de poros existentes em uma faixa de tamanho pequena, em torno de $0,1 \mu \mathrm{m}$, o que provavelmente representa a porosidade entre as lamelas 
formada pelo congelamento da água. Além disso, houve também a presença de poros maiores na amostra AL20 (Fig. 6a), na faixa de aproximadamente $20 \mu \mathrm{m}$, na amostra AL25 (Fig. 6b), na faixa de aproximadamente $10 \mu \mathrm{m}$, e na amostra AL30 (Fig. 6c), as quais provavelmente representaram as porosidades encontradas entre as estruturas dendríticas formadas. Essas alterações na morfologia dos poros podem ser melhor observadas nas micrografias apresentadas abaixo. Para as amostras AL35 (Fig. 6d) e AL40 (Fig. 6e), houve maior quantidade de sólidos e uma microestrutura porosa diferente, como é apresentado abaixo, com predominância de lamelas sem braços dendríticos; assim, as porosidades de maiores tamanhos não foram observadas nessas amostras. A alteração na morfologia das lamelas foi relacionada à quantidade de sólidos em suspensão e teve relação direta com a microestrutura porosa formada. Com uma maior quantidade de sólidos, há uma tendência à formação de estruturas mais ordenadas, portanto, uma maior tendência a um crescimento lamelar; no entanto, quanto menor a quantidade de sólidos, há maior tendência para um crescimento dendrítico [23, 38]. Isso explica a mudança da população de poros com aumento da quantidade de sólidos na suspensão.

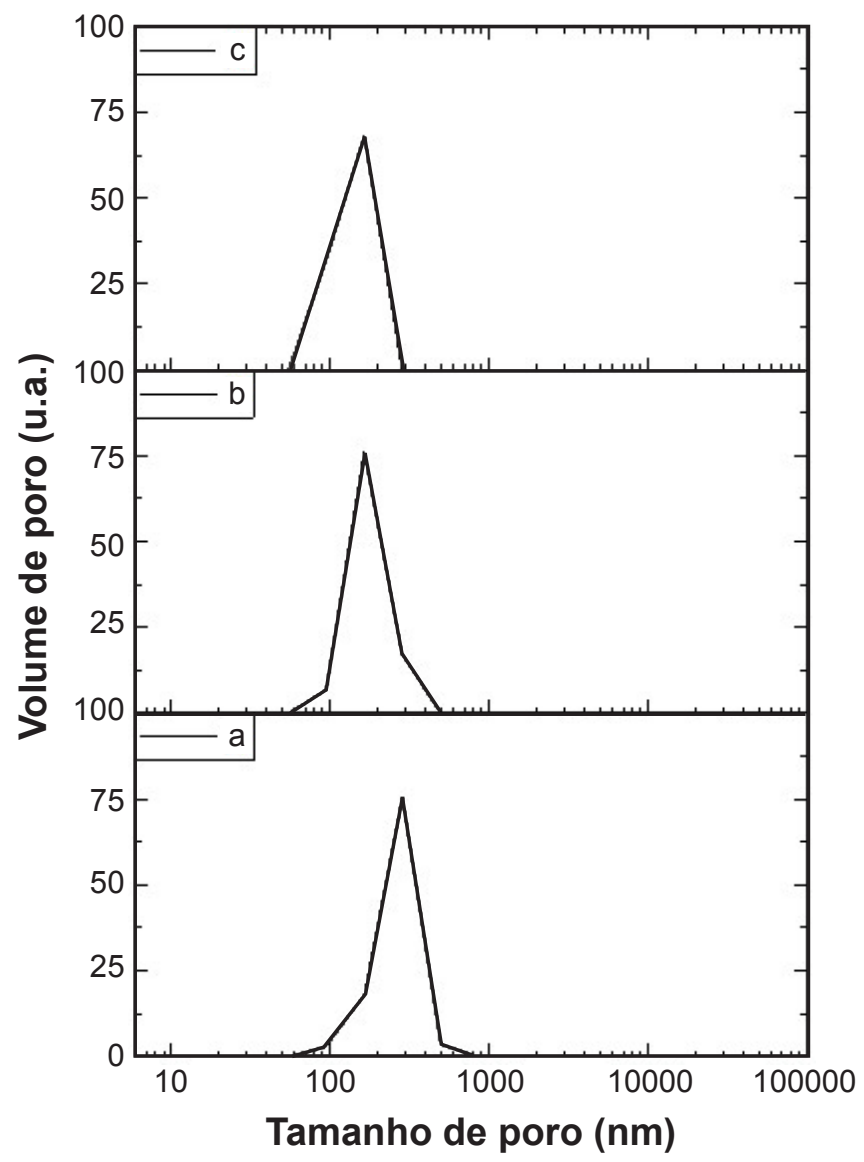

Figura 5: Curvas de distribuição de tamanho de poros das amostras com $75 \%$ (a), $50 \%$ (b) e $25 \%$ (c) de hidróxido de alumínio como fase de sacrifício.

[Figure 5: Pore size distribution curves of samples with 75\% (a), $50 \%$ (b), and $25 \%$ (c) of aluminum hydroxide as a sacrificial phase.]

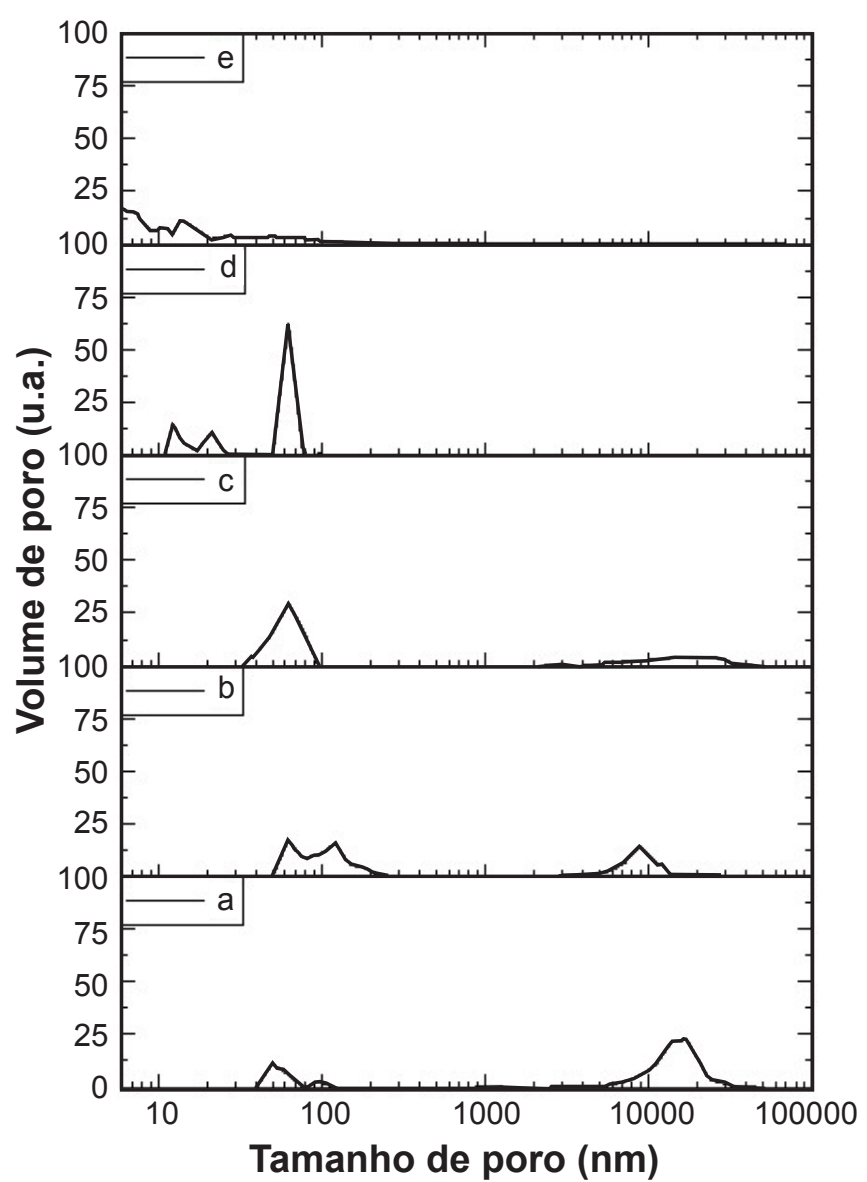

Figura 6: Curvas de distribuição de tamanho de poros das amostras preparadas por freeze-casting: a) AL20; b) AL25; c) AL30; d) AL35; e e) AL40.

[Figure 6: Pore size distribution curves of freeze cast samples: a) AL20; b) AL25; c) AL30; d) AL35; and e) AL40.]

A Fig. 7 apresenta as micrografias das amostras porosas que utilizaram hidróxido de alumínio. Pôde ser observada uma maior porosidade presente no material, quanto maior a quantidade de hidróxido de alumínio adicionada. As microestruturas apresentaram uma morfologia de poros comumente observada em materiais que utilizam hidróxido de alumínio como fase de sacrifício [17-21, 61, 62]. Nestes casos, quando sinterizados a $1500{ }^{\circ} \mathrm{C}$, os mecanismos de densificação já tem alta atuação no material, assim, os poros são formados principalmente a partir da interação entre as partículas da alumina presentes anteriormente no material e as partículas de alumina geradas a partir da decomposição do hidróxido de alumínio. Durante o processo de colagem houve o empilhamento das partículas de alumina, que foram menores, e de hidróxido de alumínio, que foram maiores. Durante o aquecimento para o processo de sinterização, as partículas de hidróxido de alumínio se decompuseram, reduzindo o volume em aproximadamente $60 \%$ e formando partículas de alumina ao redor dos poros gerados pela redução de volume [18].

Nas Figs. 8 e 9 estão apresentadas as micrografias das amostras AL20, AL25, AL30, AL35 e AL40 obtidas pelo processo de freeze casting.AFig. 8 apresenta a microestrutura 


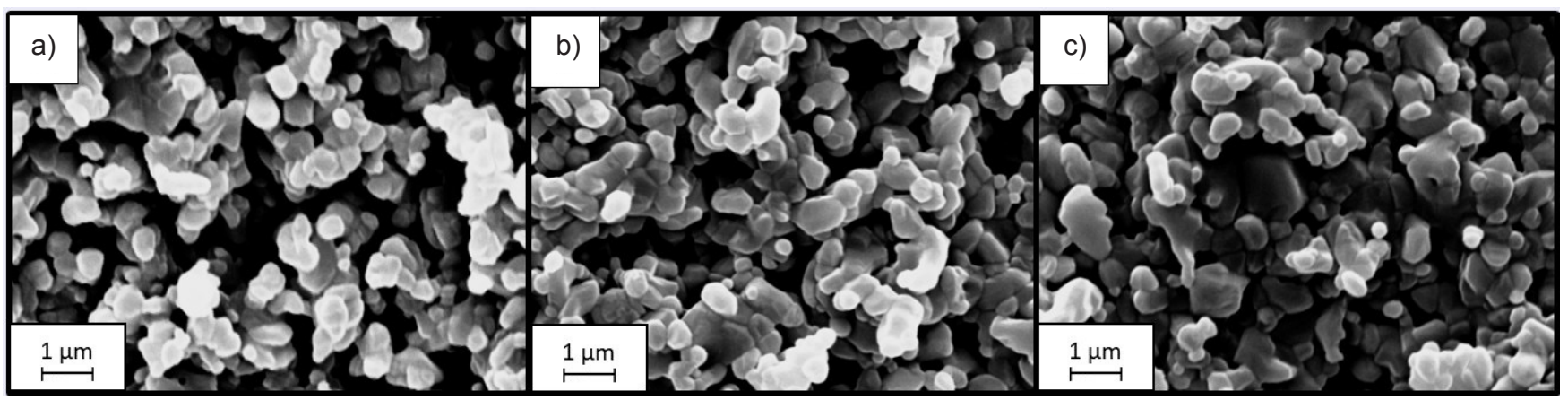

Figura 7: Imagens de MEV das amostras individuais com 25\% (a), 50\% (b) e 75\% (c) de hidróxido de alumínio como fase de sacrifício. [Figure 7: SEM images of individual samples with 25\% (a), 50\% (b), and 75\% (c) of aluminum hydroxide as sacrifice phase.]

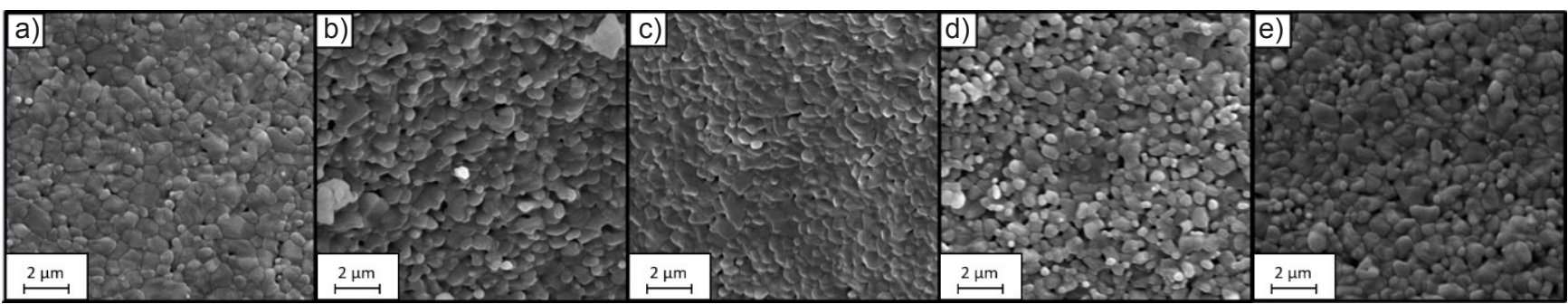

Figura 8: Imagens de MEV das microestruturas das lamelas das amostras: a) AL20; b) AL25; c) AL30; d) AL35; e e) AL40. [Figure 8: SEM images of the microstructures of the samples: a) AL20; b) AL25; c) AL30; d) AL35; and e) AL40.]

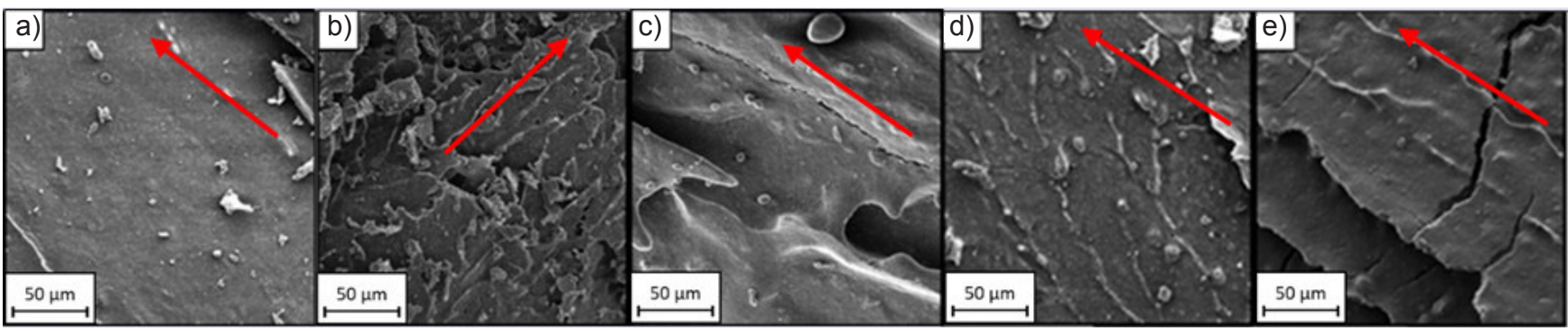

Figura 9: Imagens de MEV mostrando as morfologias de camada das amostras: a) AL20; b) AL25; c) AL30; d) AL35; e e) AL40. As setas vermelhas indicam a direção longitudinal das amostras.

[Figure 9: SEM images showing the layer morphologies of the samples: a) AL20; b) AL25; c) AL30; d) AL35; and e) AL40. The red arrows represent the longitudinal direction of the samples.]

das camadas de alumina, nas quais observam-se apenas poros de pequeno tamanho, o que foi em acordo com as curvas de distribuição de tamanho de poros apresentadas na Fig. 6. As amostras apresentaram o crescimento das lamelas na direção longitudinal, porém, com algumas diferenças morfológicas entre elas, que pode ser observado na Fig. 9. A análise de microscopia foi realizada nas superfícies de fratura das amostras, portanto, elas não representam a parte superior ou inferior da mesma, onde termina ou inicia o crescimento dos cristais. Dessa forma é possível a análise do modo de crescimento das lamelas, mas não a distância de separação entre elas. Pelas imagens é possível verificar que houve uma diferença significativa na morfologia das lamelas, sendo que as amostras com menores quantidades de sólidos apresentaram uma morfologia dendrítica (Figs. 9a a 9c) e as amostras com maiores quantidades de sólidos apresentaram uma morfologia lamelar (Figs. 9d e 9e).

A Fig. 10 apresenta micrografias de baixa magnificação da amostra graduada, produzida pelo processo de colagem sequencial utilizando hidróxido de alumínio como fase de sacrifício. Foi possível observar a diferença de porosidade entre as camadas. A camada menos porosa está representada com o índice 1 nas imagens da Fig. 10 e as camadas 2, 3 e 4 representam as camadas com adição de 25\%, 50\% e 75\% de hidróxido de alumínio, respectivamente. Observou-se que não houve defeitos evidentes, como poros e trincas, entre as camadas formadas. Esse fato pode ser melhor observado na Fig. 11, a qual apresenta as interfaces geradas no material graduado utilizando hidróxido de alumínio como fase de sacrifício. Em todas as imagens, a quantidade de hidróxido de alumínio foi maior no lado direito. Observa-se, na Fig. 11, a formação de uma interface homogênea, o que comprova que houve uma boa interação entre as camadas. Essas micrografias confirmam a possibilidade de produzir materiais com graduação de porosidade a partir de colagens de barbotina sequenciais.

Na Fig. 12 estão apresentadas as micrografias das camadas da amostra graduada processada por freeze casting. Pôde-se 


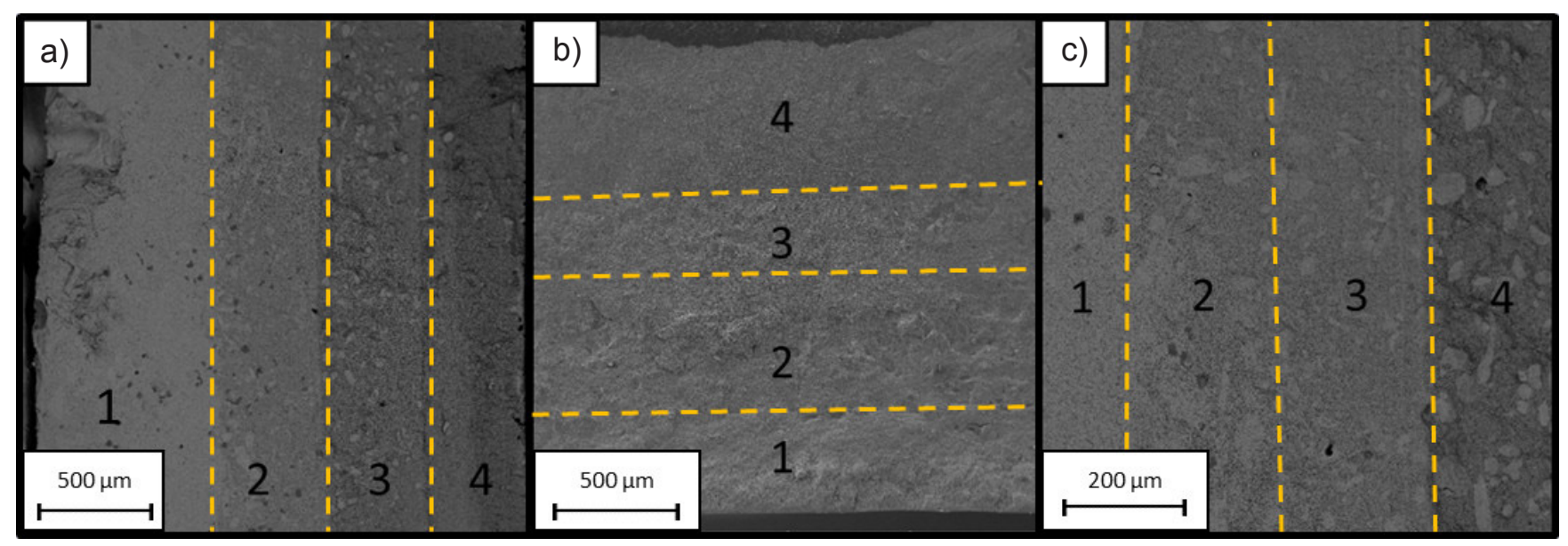

Figura 10: Imagens de MEV da amostra de alumina graduada utilizando hidróxido de alumínio como fase de sacrifício. [Figure 10: SEM images of graded alumina samples with aluminum hydroxide as sacrifice phase.]

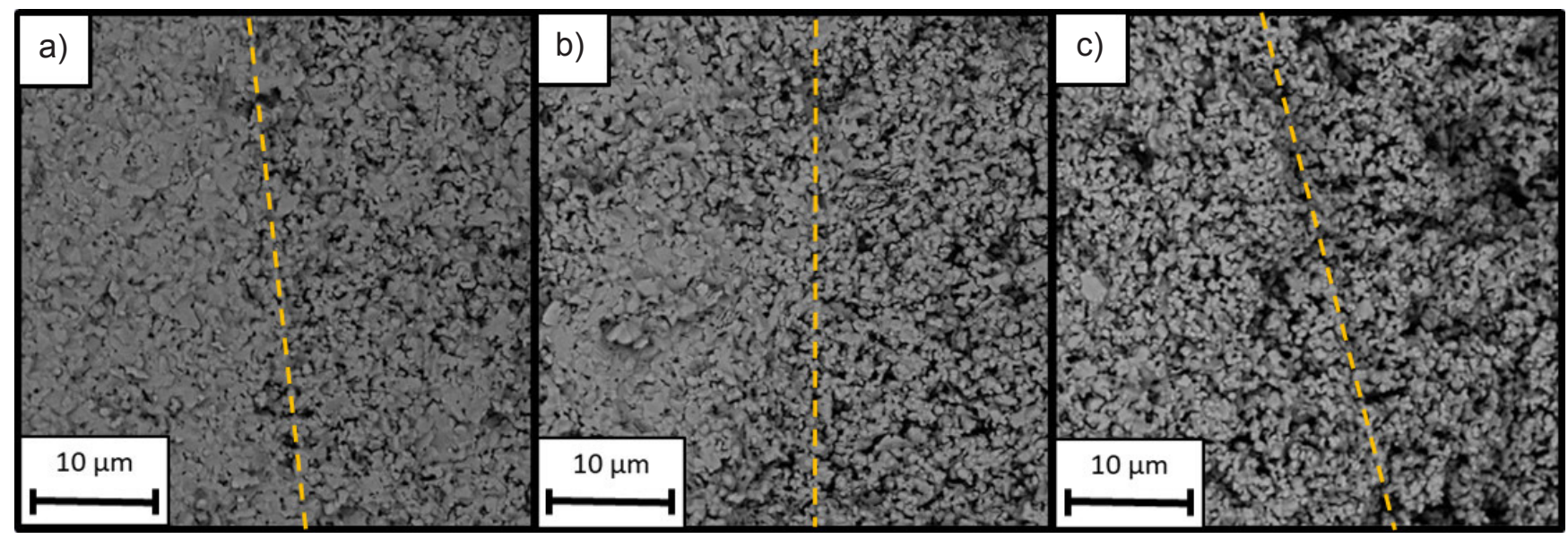

Figura11: Imagens de MEV de interfaces entre as camadas com $0 \%$ e $25 \%$ (a), $25 \%$ e $50 \%$ (b) e $50 \%$ e $75 \%$ (c) de hidróxido de alumínio. [Figure 11: SEM images of interfaces between layers with $0 \%$ and 25\% (a), 25\% and 50\% (b), and 50\% and 75\% (c) of aluminum hydroxide.]

observar a alteração da morfologia das camadas, que foi predominantemente lamelar, com vestígios de dendritas entre as lamelas, na camada mais próxima à base de congelamento (AL40) e predominantemente dendrítica, com vestígios de lamelas, na camada mais distante da base de congelamento (AL20). As morfologias porosas das amostras graduadas foram semelhantes às das camadas isoladas, apresentando algumas diferenças devido, principalmente, à relação entre nucleação e crescimento de núcleos de gelo. Isso ocorreu devido à distância entre a região da frente de propagação ou de iniciação do congelamento e a base metálica do molde resfriada pelo nitrogênio líquido. Assim, quanto mais perto do molde, maior é a nucleação de cristais, e as estruturas de gelo formadas ficam mais próximas, não permitindo desvios apresentados na estrutura dendrítica. Além da distância do molde, a quantidade de sólidos em suspensão também afeta o modo como a morfologia dos cristais de gelo se forma. Como comentado, há uma tendência maior de crescimento lamelar com maiores quantidades de sólido em suspensão e dendrítico com menores quantidades de sólido em suspensão $[23,28]$. Observou-se também que houve uma pequena quantidade de porosidade interna às camadas, de modo semelhante às suas camadas isoladas, representando que o processo de sinterização foi suficiente para gerar paredes densas das camadas cerâmicas das amostras, tanto para uma amostra de pequena espessura como para uma amostra mais espessa, com os congelamentos sequenciais permitindo que ocorresse a formação de lamelas e dendritas densas com a estrutura porosa ao redor.

As imagens de MEV das interfaces do material graduado obtido pela técnica de freeze casting estão apresentadas na Fig. 13. O material apresentou interfaces bem definidas, com boa interação e alteração da morfologia de poros conforme se afastou da base de congelamento. A interface entre as camadas AL20 e AL25 não ficou evidente, não havendo uma região determinada onde houve a alteração da microestrutura do material. Isso provavelmente ocorreu devido à posição dessas camadas no material graduado. A camada AL20 foi a última a ser formada e, por estar mais distante da face fria do molde, teve uma menor velocidade de congelamento. Devido a isso, pode ter ocorrido a fusão do gelo superficial da face superior da camada AL25 com a face inferior da camada AL20. 


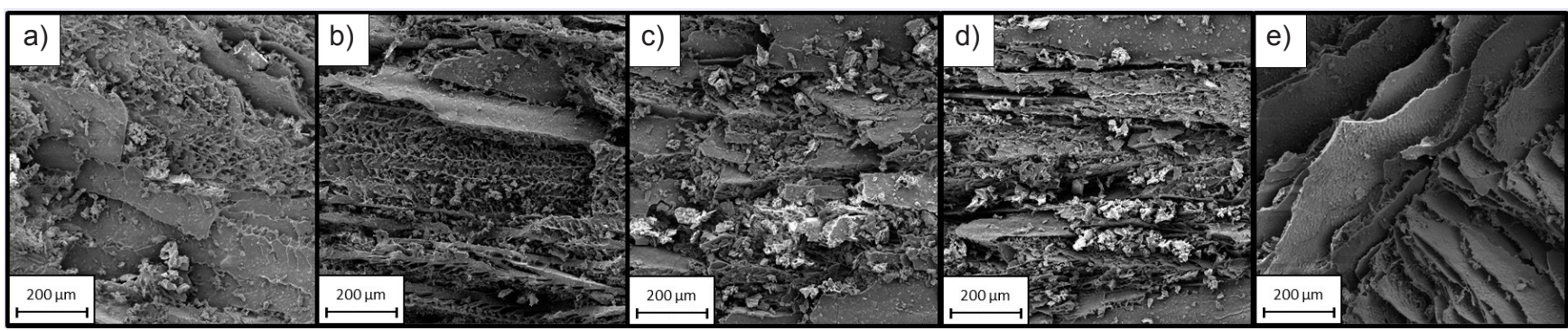

Figura 12: Imagens de MEV das camadas isoladas de: a) AL20; b) AL25; c) AL30; d) AL35; e e) AL40. [Figure 12: SEM images of isolated layers of: a) AL20; b) AL25; c) AL30; d) AL35; and e) AL40.]

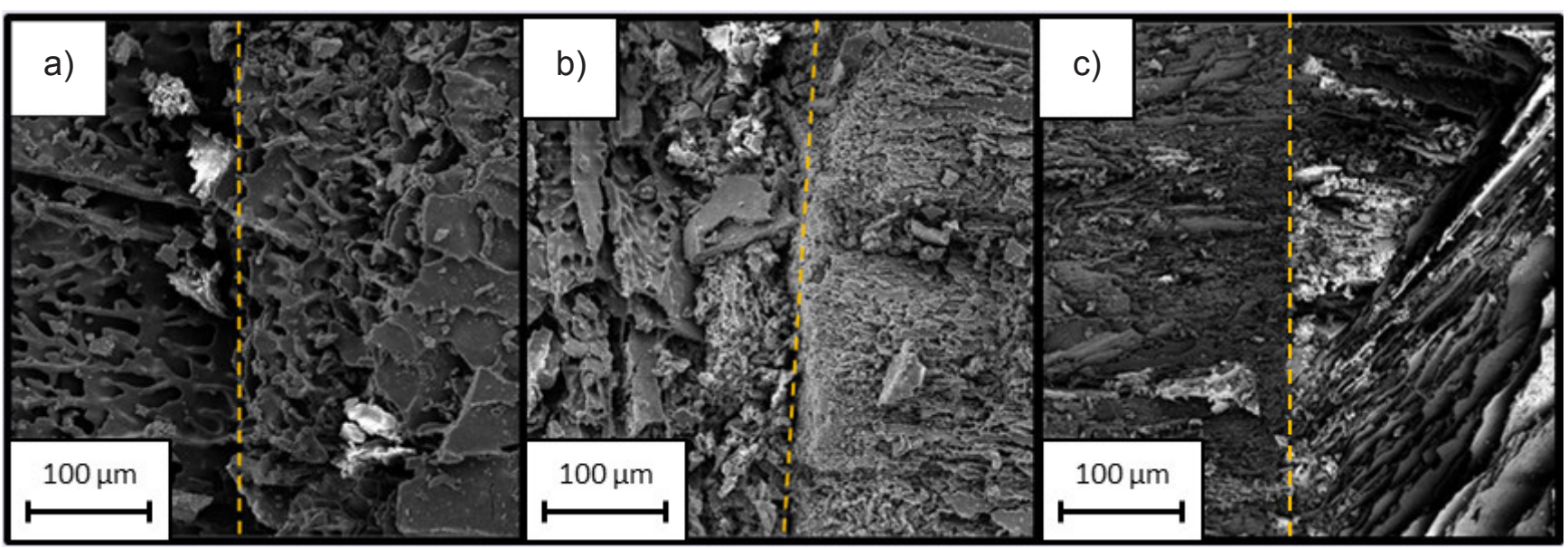

Figura 13: Imagens de MEV das interfaces da alumina graduada obtida pela técnica de freeze casting: a) AL25 e AL30; b) AL30 e AL35; c) AL35 e AL40 (as linhas amarelas pontilhadas demonstram as interfaces entre as camadas).

[Figure 13: SEM images of interfaces of graded alumina obtained by the freeze casting technique: a) AL25 and AL30; b) AL30 and AL35; c) AL35 and AL4O (dotted lines show the interfaces between layers).]

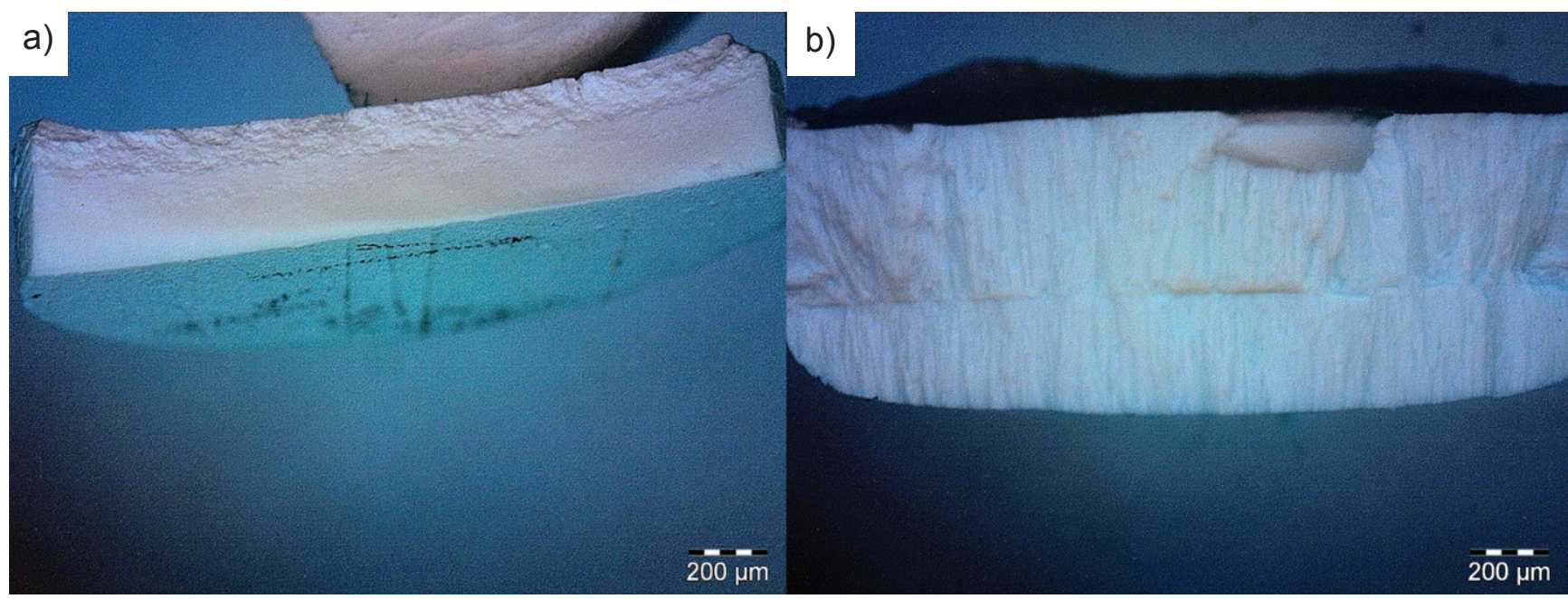

Figura 14: Micrografias óticas de superfícies de fratura das amostras graduadas obtidas por: a) colagem de barbotina; e b) freeze casting . [Figure 14: Optical micrographs of fracture surfaces of graded samples obtained by: a) slip casting; and b) freeze casting.]

$\mathrm{Na}$ Fig. 14 estão apresentadas as imagens das superfícies de fratura das amostras graduadas produzidas pelo processo de colagem de barbotina sequencial e utilizando hidróxido de alumínio como fase de sacrifício e por freeze casting. As amostras tiveram fratura no sentido longitudinal, mesmo sentido onde se deu o gradiente de porosidade, assim, confirmando a homogeneidade das interfaces comentada anteriormente. Como pode ser observado não houve lascamento ou quebra no sentido transversal em ambas as amostras. Foi possível também verificar a influência do formato e tamanho de poros, visto anteriormente, nas superfícies de fratura. Com poros menores obtidos pelo processo de colagem de barbotina (Fig. 14a), observou-se uma superfície de 
fratura relativamente homogênea e, com poros maiores e interconectados obtidos pelo processo de freeze casting (Fig. 14b), observou-se uma superfície mais acidentada e com ranhuras.

$\mathrm{O}$ valor de resistência à compressão alcançado pelas amostras graduadas foi de $12 \mathrm{MPa}$ para as amostras produzidas utilizando hidróxido de alumínio como fase de sacrifício e de $18 \mathrm{MPa}$ para as amostras graduadas produzidas por freeze casting. Uma possível explicação para a maior resistência mecânica apresentada pela amostra produzida por freeze casting está relacionado ao formato dos poros. Nas amostras obtidas por colagem de barbotina os poros tiveram morfologia próxima à esférica, enquanto nas obtidas por freeze casting a morfologia foi alinhada, no sentido longitudinal da amostra. O ensaio de compressão foi realizado no sentido longitudinal das amostras, conforme observado na Fig. 14, o que conferiu uma maior resistência devido a uma menor concentração de tensão e dificuldade para movimento de trincas no interior do material $[50,51]$.

\section{CONCLUSÕES}

Cerâmicas de alumina porosas graduadas foram preparadas com sucesso utilizando dois processos: a colagem de barbotina sequencial utilizando hidróxido de alumínio como fase de sacrifício e o processo de freeze casting. As interfaces entre as camadas das cerâmicas graduadas mostraram-se bem definidas e apresentaram uma transição homogênea de porosidade. A análise de superfície de fratura também mostrou que não houve lascamento do material ou falha no sentido transversal ao gradiente de porosidade. A porosidade das cerâmicas de alumina foi principalmente aberta para os dois processos, sendo que a diferença foi na morfologia dos poros. No processo de colagem de barbotina, os poros apresentaram-se com menores tamanhos, havendo um aumento da porosidade com o aumento da quantidade de hidróxido de alumínio adicionado. No processo de freeze casting os poros apresentaram-se predominantemente abertos, interconectados e alinhados, com morfologias lamelares ou dendríticas, dependentes da quantidade de sólido presente na suspensão. A resistência mecânica das amostras graduadas obtidas pela técnica de freeze casting foi maior que as amostras produzidas por colagem de barbotina. Essa diferença se deu principalmente pelo formato dos poros obtidos para cada um dos processos estudados. Para a processo de freeze casting, a porosidade teve morfologia alinhada na direção em que foi realizado o ensaio de compressão, enquanto para a técnica de colagem de barbotina os poros tiveram formato próximo ao esférico. Os dois processos estudados mostraram ser de fácil processamento e foram eficientes para a produção de cerâmicas de alumina porosas graduadas. Esses resultados mostraram a viabilidade de aplicação desse material em diferentes áreas como materiais estruturais leves e isolantes térmicos, além da área de biomateriais.

\section{AGRADECIMENTOS}

This study was financed in part by the Coordenação de Aperfeiçoamento de Pessoal de Nível Superior - Brasil (CAPES) - Finance Code 001.

\section{REFERÊNCIAS}

[1] M.A.F. Afzal, P. Kesarwani, K.M. Reddy, S. Kalmodia, Mater. Sci. Eng. C 32, 5 (2012) 1164.

[2] A. Mali, A. Petric, J. Power Sources 196, 11 (2011) 5191.

[3] P. We, S. Sofie, Q. Zhang, A. Petric, Proc. 219 Electrochem. Soc. Meet. 35, 1 (2011) 379.

[4] J. Garcia-Fayos, V.B. Vert, M. Balaguer, C. Solís, C. Gaudillere, Catal. Today 257, P2 (2014) 221.

[5] R. Liu, T. Xu, C. Wang, Ceram. Int. 42 (2016) 2907.

[6] L.C. Hwa, S. Rajoo, A.M. Noor, N. Ahmad, M.B. Uday, Curr. Opin. Solid State Mater. Sci. 21 (2017) 323.

[7] R.K. Nishihora, P.L. Rachadel, M.G.N. Quadri, D. Hotza, J. Eur. Ceram. Soc. 38 (2018) 988.

[8] E. Babaie, S.B. Bhaduri, ACS Biomater. Sci. Eng. 4 (2018) 1.

[9] W.E. Lee, Ceramic microstructures: property control by processing, Chapman Hall, London (1994) 590.

[10] A.R. Studart, U.T. Gonzenbach, E. Tervoort, L.J. Gauckler, J. Am. Ceram. Soc. 89, 6 (2006) 1771.

[11] N. Hedayat, Y. Du, H. Ilkhani, Renew. Sust. Energ. Rev. 77 (2017) 1221.

[12] T. Shirai, H. Watanabe, M. Fuji, M. Takahashi, Ann. Rep. Adv. Ceram. Res. Cent. Nagoya Inst. Technol. 9 (2009) 23.

[13] K. Wefers, C. Misra, "Oxides and hydroxides of aluminum", Alcoa Techn. Paper, 19, Alcoa Lab., San Diego (1987).

[14] V.R. Damerell, F. Hovorka, W.E.J. White, J. Phys. Chem. 36 (1932) 1255.

[15] J.M.R. Mercury, P. Pena, A.H. de Aza, J. Am. Ceram. Soc. 89, 12 (2006) 3728.

[16] B.K. Gan, I.C. Madsen, J.G. Hockridge, J. Appl. Crystallogr. 42, 4 (2009) 697.

[17] M.H. Stacey, J. Am. Chem. Soc. 3, 5 (1987) 681.

[18] Z.-Y. Deng, T. Fukasawa, M. Ando, J. Am. Ceram. Soc. 84, 11 (2001) 2638.

[19] A.D.V. Souza, R. Salomão, J. Eur. Ceram. Soc. 36 (2016) 885.

[20] R.V. Levkov, S.N. Kulkov, IOP Conf. Ser. Mater. Sci. Eng. 175 (2017) 12045.

[21] I.A.Zhukov, E.S. Dedova, S.P. Buyakova, S.N. Kulkov, R.V. Levkov, G. Mamontov, V. Promakhov, Orient. J. Chem. 32, 1 (2016) 93.

[22] Y. Zhang, L. Hu, J. Han, Ceram. Int. 36 (2010) 617.

[23] S. Deville, Adv. Eng. Mater. 10, 3 (2008) 155.

[24] N. Arai, K.T. Faber, Scripta Mater. 162 (2019) 72.

[25] C. Gaudillere, J.M. Serra, Bol. Soc. Esp. Ceram. V. 55 (2016) 45

[26] Z. Wu, Z. Zhou, Y. Hong, J. Adv. Ceram. 8 (2019) 256.

[27] T. Xu, C. Wang, Mater. Des. 91 (2016) 242. 
[28] Y. Tang, M. Mao, S. Qiu, K. Zhao, Ceram. Int. 44 (2018) 1187.

[29] Y. Tang, M. Mao, S. Qiu, C. Wu, J. Eur. Ceram. Soc. 38 (2018) 4149.

[30] Y. Tang, M. Mao, S. Qiu, K. Zhao, W. Chen, Ceram. Int. 44 (2018) 17566.

[31] Y. Tang, S. Qiu, C. Wu, Q. Miao, K. Zhao, J. Eur. Ceram. Soc. 36 (2016) 1513.

[32] M. Naviroj, P.W. Voorhees, K.T. Faber, J. Mater. Res. 32 (2017) 3372.

[33] L. Hu, C. Wang, Y. Huang, C. Sun, S. Lu, Z. Hu, J. Eur. Ceram. Soc. 30, 16 (2010) 3389.

[34] Y. Koh, E. Lee, B. Yoon, J. Song, H.J. Kim, J. Am. Ceram. Soc. 89, 12 (2006) 3646.

[35] K. Araki, J.W. Halloran, J. Am. Ceram. Soc. 88, 5 (2005) 1108.

[36] T. Fukasawa, M. Ando, J. Am. Ceram. Soc. 84, 1 (2001) 230.

[37] A. Preiss, B. Su, S. Collins, D. Simpson, J. Eur. Ceram. Soc. 32, 8 (2012) 1575.

[38] D. Li, M. Li, J. Porous Mater. 19, 3 (2012) 345.

[39] S. Deville, E. Saiz, A.P. Tomsia, Acta Mater. 55, 6 (2007) 1965.

[40] K. Araki, J.W. Halloran, J. Am. Ceram. Soc. 87, 11 (2004) 2014.

[41] R. Chen, C. Wang, Y. Huang, L. Ma, W. Lin, J. Am. Ceram. Soc. 90, 11 (2007) 3478.

[42] S.W. Sofie, J. Am. Ceram. Soc. 90, 7 (2007) 2024.

[43] G. Shi, Z. Wu, C. Jiang, S. Peng, J. Yan, Z. Wang, Mater. Lett. 161 (2015) 580.

[44] Y. Tang, Q. Miao, S. Qiu, K. Zhao, L. Hu, J. Eur. Ceram. Soc. 34 (2014) 4077.

[45] A. Toudehdehghan, J.W. Lim, K.E. Foo, M.I.N. Maarof, J. Mathews, MATEC Web Conf. 131 (2017) 3010.

[46] M. Naebe, K. Shirvanimoghaddam, Appl. Mater. Today 5 (2016) 223.
[47] C. Zhang F. Chen, Z. Huang, M. Jia, G. Chen, Y. Ye, Y. Lin, W. Liu, B. Chen, Q. Shen, L. Zhang, E.J. Lavernia, Mater. Sci. Eng. A 764 (2019) 138209.

[48] D.T. Sarathchandra, S.K. Subbu, N. Venkaiah, Mater. Today Proc. 5, 10 (2018) 21328.

[49] T. Dai, H. Dai, Z. Lin, Compos. Struct. 210 (2019) 641. [50] E. Schwarzer, S. Holtzhausen, W. Scheithauer, C. Ortmann, T. Oberbach, T. Moritz, A. Michaelis, J. Eur. Ceram. Soc. 39 (2019) 522.

[51] C. Morin, S. Le Gallet, M. Ariane, F. Bernard, Ceram. Int. 42 (2016) 3056.

[52] P. Gonzalez, E. Schwarzer, U. Scheithauer, N. Kooijmans, T. Moritz, J. Vis. Exp. 143 (2019) e57943.

[53] W.S. Ebhota, A.S. Karun, F.L. Inambao, Int. J. Eng. Res. Afr. 26 (2016) 47.

[54] C.D. Christiansen, K.K. Nielsen, R. Bjork, J. Eur. Ceram. Soc. 40 (2020) 1398.

[55] C. Madec, S. Le Gallet, B. Salesse, N. Geoffroy, F. Bernard, J. Mater. Process. Technol. 254 (2018) 277.

[56] C. Huang, Y. Chen, Int. J. Refract. Hard Met. 67 (2017) 129.

[57] J.A.M. Pereira, M. Schwaab, E. Dell'Oro, J.C. Pinto, J.L.F. Monteiro, C.A. Henriques, Hydrometallurgy 96 (2009) 6.

[58] I.N. Bhattacharya, S.C. Das, P.S. Mukherjee, S. Paul, P.K. Mitra, Scand. J. Metall. 33 (2004) 211.

[59] F.F. Lange, J. Am. Ceram. Soc. 67, 2 (1984) 83.

[60] W.D. Kingery, H.K. Bowen, D.R. Uhlmann, Introduction to ceramics, Wiley-Intersci., New York (1976) 1056.

[61] A.D.V. Souza, C.C. Arruda, L. Fernandes, M.L.P. Antunes, P.K. Kiyohara, R. Salomão, J. Eur. Ceram. Soc. 35, 2 (2015) 803.

[62] Z.Y. Deng, T. Fukasawa, M. Ando, J. Am. Ceram. Soc. 84, 3 (2001) 485.

(Rec. 14/10/2019, Rev.06/01/2020, 26/05/2020, 17/09/2020, Ac. 23/09/2020) 